\title{
Is age group a predictive factor for satisfaction among patients undergoing sympathectomy to treat hyperhidrosis?
}

\author{
A idade é um fator preditivo de satisfação entre pacientes \\ submetidos à simpatectomia para o tratamento da hiper-hidrose?
}

José Ribas Milanez de Campos', Nelson Wolosker², Marco Antonio Soares Munia², Guilherme Yazbek², Paulo Kauffman², Pedro Puech-Leão², Fábio Biscegli Jatene $e^{3}$

\begin{abstract}
Objective: Video-assisted thoracic sympathectomy is currently the procedure of choice for the definitive treatment of primary hyperhidrosis, because it is an effective, safe, and minimally invasive method. In the search for better quality of life indexes, all researchers look for predictive factors indicating better surgical outcomes. Failure in the primary treatment, postoperative compensatory hyperhidrosis, body mass index over 25 , level of resection of the sympathetic chain, and extent of resection are some of the factors that may negatively influence the results. The objective of this study was to compare, according to the age group, the quality of life after bilateral thoracic sympathectomy for treatment of primary hyperhidrosis in a cohort of 1,644 patients. Methods: From February 2000 to October 2008, data were collected from 1,644 patients with palmar (71\%) or axillary (29\%) hyperhidrosis who underwent video-assisted thoracic sympathectomy. The patients were divided into three groups according to their ages. The first group consisted of patients up to 17 years-old, the second from 18 to 30 years-old, and the third of over 30 years-old. All patients had a body mass index of less than 25. Results: In the evaluation 30 days after surgery, improvement of the quality of life in the three groups was observed. There was no significant difference between the age groups. In the present study, 91.9\% of the patients presented compensatory hyperhidrosis, with no difference between the age groups. Conclusions: Patients with primary hyperhidrosis experience quality of life improvement after thoracic sympathectomy regardless of their age.
\end{abstract}

Keywords: hyperhidrosis; sympathectomy; quality of life; age.

\section{Resumo}

Objetivo: A simpatectomia torácica por videotoracoscopia é atualmente o procedimento de escolha para o tratamento definitivo da hiper-hidrose palmar, pois é um método eficaz, seguro e minimamente invasivo. Na busca de melhores índices de qualidade de vida, os pesquisadores procuram por fatores preditivos de bom resultado cirúrgico. A falência do tratamento inicial, a hiper-hidrose compensatória, o índice de massa corpóreo acima de 25, o nível de ressecção ganglionar e a extensão da ressecção são alguns dos fatores que podem influenciar negativamente os resultados. $\mathrm{O}$ objetivo deste estudo foi comparar a qualidade de vida dos pacientes submetidos à simpatectomia torácica, de acordo com a faixa etária, numa coorte com 1.644 pacientes.

Métodos: De fevereiro de 2000 a outubro de 2008, foram colhidos dados de 1.644 pacientes portadores de hiper-hidrose palmar (71\%) ou axilar (29\%), submetidos à simpatectomia torácica por videotoracoscopia. Os pacientes foram divididos em três grupos de acordo com a idade. O primeiro grupo foi de pacientes com até 17 anos, o segundo de 18 a 30 anos, e o terceiro com pacientes com mais de 30 anos de idade. Todos os pacientes tinham índice de massa corpóreo menor que 25.

Resultados: Numa avaliação 30 dias após o procedimento, a melhora da qualidade de vida foi obtida nos três grupos. Não houve diferença estatística entre as diferentes faixas etárias. Neste estudo, 91,9\% dos pacientes apresentaram algum grau de hiper-hidrose compensatória, novamente sem diferença entre os grupos.

Conclusões: Pacientes portadores de hiper-hidrose primária apresentam melhora da qualidade de vida após o procedimento cirúrgico independentemente de sua idade.

Palavras-chave: hiper-hidrose; simpatectomia; qualidade de vida; idade.

Study carried out at the Ambulatório de Hiper-hidrose do Hospital das Clínicas da Faculdade de Medicina da USP.

${ }^{1}$ Hospital das Clínicas, Heart Institute - Incor, University of São Paulo Medical School.

${ }^{2}$ Department of Vascular Surgery, Hospital das Clínicas, University of São Paulo Medical School.

${ }^{3}$ Department of Thoracic Surgery, Hospital das Clínicas, Heart Institute - Incor, University of São Paulo Medical School.

Financial support: none.

Conflict of interest: nothing to declare.

Submitted on: 06/10/2010. Accepted on: 08/08/2011.

J Vasc Bras. 2011;10(4):284-288. 


\section{Introduction}

Video-assisted thoracic sympathectomy (VATS) is currently the procedure of choice for the definitive treatment of primary hyperhidrosis, because it is an effective, safe, and minimally invasive method ${ }^{1}$. Since the introduction of VATS in the 1990s, this therapeutic modality has been used with increasing frequency, with good results regardless of the patient's age ${ }^{2}$. The aim of the treatment is to improve the quality of life, by reducing excessive sudoresis.

In search of better quality of life indexes, all researchers look for predictive factors indicating better surgical outcomes. Failure in the primary treatment ${ }^{3}$, postoperative compensatory hyperhidrosis ${ }^{4}$, body mass index over $25^{5}$, level of resection of the sympathetic chain, and extent of resection ${ }^{4,5}$ are some of the factors that may negatively influence the results.

Treatment using VATS of children yields satisfactory results comparable to results obtained with adults ${ }^{6}$. Only one article reports a greater postprocedure satisfaction index in a group of young women, linking the result to a lower incidence of compensatory hyperhidrosis ${ }^{7}$. Specifically regarding age, there are no studies that compare objectively the postoperative quality of life of a large group of patients treated by the same surgical team.

The objective of this study was to compare, according to the age group, the quality of life after bilateral thoracic sympathectomy for treatment of primary hyperhidrosis in a cohort of 1,644 patients.

\section{Patients and Methods}

From February 2000 to October 2008, data were collected from 1,644 patients with palmar (71\%) or axillary (29\%) hyperhidrosis who underwent VATS.

Patients were divided into three groups according to their ages. The first group consisted of patients up to 17 years-old, the second from 18 to 30 years-old, and the third of over 30 years-old. All the patients had a body mass index of less than $25^{5}$. The patients' distribution, according to age and gender, is presented in Table 1.

All the patients underwent two evaluations for the purpose of this study: before the surgery and one month after it. In each visit, patients were given a clinical protocol to assess quality of life ${ }^{2}$. The incidence and intensity of compensatory hyperhidrosis were also studied in the postoperative evaluation.

The protocol for assessment of quality of life administered to all patients presented daily life situations in which hyperhidrosis might interfere. Quality of life was initially classified into five different satisfaction levels, which were obtained as the summed total score from the protocol (range from 20 to 100). When the total score was greater than 84 , the quality of life was considered very poor; from 69 to 84 , poor; from 52 to 68 , good; from 36 to 51 , very good; and from 20 to 35, excellent. The patients' postoperative evolutions (one month) were classified into five different satisfaction levels, which were calculated as the summed total score from the questionnaire. When the total was greater than 84 , the quality of life was considered much worse; from 69 to

Table 1. A descriptive analysis of each age group.

\begin{tabular}{|c|c|c|c|c|c|}
\hline Age group & Up to 17 years & 18 to 30 years & Over 30 years & Total & $\mathrm{p}$ \\
\hline \multicolumn{6}{|l|}{ Age (years) } \\
\hline Mean $\pm D P$ & $15.3 \pm 2.0$ & $23.2 \pm 3.4$ & $37.3 \pm 6.3$ & $25.0 \pm 7.8$ & \multirow{4}{*}{$\mathrm{p} 1<0.001$} \\
\hline Median & 16 & 23 & 35 & 23 & \\
\hline Minimum-Maximum & $8-17$ & $18-30$ & $31-70$ & $8-70$ & \\
\hline Total of patients & 218 & 1094 & 332 & 1644 & \\
\hline \multicolumn{6}{|l|}{ Gender - n (\%) } \\
\hline Female & $151(69.3)$ & $755(69.0)$ & $217(65.4)$ & $1130(67.7)$ & \multirow{3}{*}{$\mathrm{p} 2=0.433$} \\
\hline Male & $67(30.7)$ & $339(31.0)$ & $115(34.6)$ & $530(31.7)$ & \\
\hline Total of patients & 218 & 1094 & 332 & 1644 & \\
\hline \multicolumn{6}{|l|}{ Resection Level - n (\%) } \\
\hline $\mathrm{G} 2$ & $16(7.4)$ & $55(5.0)$ & $24(7.1)$ & $95(5.8)$ & \multirow{6}{*}{$\mathrm{p} 2<0.001$} \\
\hline G2/G3 & $42(19.1)$ & $222(20.4)$ & $98(29.4)$ & $366(22.3)$ & \\
\hline G3 & $77(35.3)$ & $369(33.7)$ & $81(24.5)$ & $525(31.9)$ & \\
\hline $\mathrm{G} 3 / \mathrm{G} 4$ & $27(12.6)$ & $159(14.6)$ & $66(19.9)$ & $257(15.7)$ & \\
\hline G4 & $56(25.6)$ & $289(26.3)$ & $63(19.0)$ & $401(24.4)$ & \\
\hline Total of patients & 218 & 1094 & 332 & 1644 & \\
\hline
\end{tabular}

p1 - ANOVA; p2 - chi-square test 
84, a little worse; from 52 to 68 , the same; from 36 to 51 , a little better; and from 20 to 35, much better ${ }^{2}$.

The statistical test used to evaluate frequency data was the $\chi^{2}$ test. For continuous data (ages), we used ANOVA. We considered a $\mathrm{p} \leq 0.05$ to indicate a statistically significant difference between groups.

\section{Results}

All the patients underwent similar treatment before surgery following the same protocol except for the level of ganglion resection, which varied according to the location of the diaphoresis. The treatment was in accordance with the hospital's ethical standards as set by the Ethics Committee for Analysis of Research Projects on Human Experimentation.

All participants underwent a bilateral VATS with two 5-mm incisions. The first incision was made in the fourth submammary intercostal space to introduce the camera $\left(30^{\circ}\right)$, and the second was in the second mid-axillary intercostal space to allow for the insertion of surgical instruments ${ }^{8,9}$. Ablation, with the use of an electrical or harmonic scalpel, was the chosen technique in all cases.

The three groups were similar regarding distribution before surgery by gender, with a predominance of women. There was no significant difference regarding the type of surgery performed between patients younger than 17 yearsold, and the group between 18 and 30 years-old. The group of patients over 30 years-old underwent a greater number of G2/G3 and G3/G4 resections than the other two. No mortality or conversion to open surgery occurred in this series.

The patients' distribution, according to their postsurgical compensatory hyperhidrosis, is presented in Table 2.

The ratios of compensatory hyperhidrosis occurrence were similar in the three age groups. The intensity of compensatory hyperhidrosis according to age is presented in Table 3. We observed that the older the patient, the greater the compensatory hyperhidrosis intensity. The distribution of quality of life in the three groups is presented in Table 4 .

All the patients who underwent surgery presented low quality of life in the preoperative period and they were classified in the categories poor or very poor, with predominance of the latter, regardless of the observed age group. There was no significant difference between the age groups (Table 4).

The distribution of the quality of life after 30 days of the surgery is presented in Table 5.

In the evaluation that happened 30 days after surgery, improvement of the quality of life in the three groups was observed. There was no significant difference between the age groups.

\section{Discussion}

Surgical treatment of hyperhidrosis with VATS provides a definitive resolution of the disease and a low incidence of

Table 2. Compensatory hyperhidrosis by age group.

\begin{tabular}{|c|c|c|c|c|}
\hline Age group & Up to 17 years & 18 to 30 years & Over 30 years & Total \\
\hline \multicolumn{5}{|c|}{ Compensatory hyperhidrosis } \\
\hline Absent & $22(10.9 \%)$ & $78(7.7 \%)$ & $23(7.5 \%)$ & $123(8.1 \%)$ \\
\hline Present & $180(89.1 \%)$ & $929(92.3 \%)$ & 283 (92.5\%) & 1392 (91.9\%) \\
\hline Total & 202 & 1007 & 306 & 1515 \\
\hline
\end{tabular}

$\mathrm{p}=0.299$.

Table 3. Intensity of compensatory hyperhidrosis by age group.

\begin{tabular}{lcccc}
\hline Age Group & Up to 17 years & 18 to 30 years & Over 30 years & Total \\
\hline Intensity of Compensatory Hyperhidrosis & & & & \\
Mild & $57(32.4 \%)$ & $291(31.9 \%)$ & $73(26.5 \%)$ & $421(30.9 \%)$ \\
Moderate & $84(47.7 \%)$ & $377(41.3 \%)$ & $107(38.9 \%)$ & $568(41.6 \%)$ \\
Severe & $35(19.9 \%)$ & $245(26.8 \%)$ & $95(34.5 \%)$ & $375(27.5 \%)$ \\
Total & 176 & 913 & 275 & 1374 \\
\hline
\end{tabular}

$\mathrm{p}=0.011$.

Table 4. Quality of life before surgery, by age group.

\begin{tabular}{|c|c|c|c|c|}
\hline Quality of life & Up to 17 years & 18 to 30 years & Over 30 years & Total \\
\hline Poor & $48(22.2 \%)$ & $301(27.5 \%)$ & 85 (25.5\%) & $434(26.4 \%)$ \\
\hline Very poor & $170(77.8 \%)$ & 793 (72.5\%) & $247(74.5 \%)$ & $1210(73.6 \%)$ \\
\hline Total of patients & 218 & 1094 & 332 & 1644 \\
\hline
\end{tabular}

$p=0.299$. 
Table 5. Quality of life 30 days after surgery, by age group.

\begin{tabular}{|c|c|c|c|c|}
\hline Quality of life & Up to 17 years & 18 to 30 years & Over 30 years & Total \\
\hline Much better & $147(67.3 \%)$ & $634(57.9 \%)$ & $241(72.7 \%)$ & $1022(68.8 \%)$ \\
\hline Slightly better & $57(26.2 \%)$ & $414(37.8 \%)$ & $71(21.3 \%)$ & $542(26.3 \%)$ \\
\hline The same & $10(4.6 \%)$ & $28(2.6 \%)$ & $16(4.8 \%)$ & $54(3.3 \%)$ \\
\hline Slightly worse & $3(1.4 \%)$ & $13(1.2 \%)$ & $4(1.2 \%)$ & $20(1.2 \%)$ \\
\hline Much worse & $1(0.5 \%)$ & $5(0.5 \%)$ & $0(0.0 \%)$ & $6(0.4 \%)$ \\
\hline Total of patients & 218 & 1094 & 332 & 1644 \\
\hline
\end{tabular}

$\mathrm{p}=0.395$.

compensatory hyperhidrosis, so more and more individuals are being treated at an earlier stage in life. Consequently, a great number of patients in different age groups has been treated ${ }^{10,11}$.

Most patients who seek treatment for hyperhidrosis are young because of the discomfort, discrimination, and social isolation they face due to their condition at this stage of life $^{12}$. Since clinical treatment is palliative and it might not generate good results, sympathectomy can be regarded as the best therapeutic alternative. The fear of submitting a child or an adolescent to the surgical procedure, even though it is considered definitive by the parents, is the reason why most patients undergo surgery only as young adults (between the $18^{\text {th }}$ and $30^{\text {th }}$ year of life).

All the patients in this study came from the same clinic and were treated by the same surgical team, with similar technical criteria being respected for all the groups ${ }^{13}$. The level of resection used in each in case was considered the best when the surgeries were performed ${ }^{14}$, according to worldwide literature ${ }^{8,11}$. For example, regarding treatment for palmar hyperhidrosis, until 2002 it was treated with resection of thoracic ganglias T2 and T3; in 2003, resection of T2 only; from 2004 to 2005, of T3; and as of 2006, of T4. Nevertheless, we were able to obtain good results in the treatment of the disease regardless of the age group, according to most of the published literature ${ }^{15,16}$. Among patients under 30 years of age, there was no difference regarding the level of resection. However, in the patients older than 30 , there was a greater prevalence of $\mathrm{T} 2 / \mathrm{T} 3$ and $\mathrm{T} 3 / \mathrm{T} 4$ resections, which were used in the initial phase of our activity when only older individuals underwent surgery.

We currently know that regardless of the resection level most patients present some degree of compensatory hyperhidrosis ${ }^{17}$. In this study, $91.9 \%$ of the patients presented any degree of compensatory hyperhidrosis, with no difference between the age groups.

The intensity of compensatory hyperhidrosis was more severe in the group of individuals over 30 years of age, possibly because of the resection of two thoracic ganglia (T2/T3 and T3/T4), which was done more frequently than in the other groups.
In all the age groups, we observed a female predominance, which can be explained by the greater aesthetic-social concern shown by these patients.

It is well-established in the literature that patients with hyperhidrosis experience a poor quality of life and the surgical outcome depends on the resolution of the symptoms and severity of compensatory hyperhidrosis, as well as on how the patients adapt to this new condition of life. Although some individuals with mild compensatory hyperhidrosis may report a very poor quality of life, others, with even a severe case of hyperhidrosis, may report a better level of quality of life (adapted patients). Herein, we only performed the surgery on patients whose quality of life was classified as poor or very poor, therefore, any improvement in primary symptoms leads to an increase in quality of life.

In the postoperative period, if no technical complications occurred, there was a substantial improvement in the patients' daily lives, as indicated not only by the therapeutic success, but also by the satisfaction of the individuals and the improvement in the quality of life in all the age groups, even with the occurrence of compensatory hyperhidrosis ${ }^{18-20}$.

Generic methods of assessing the quality of life, such as the SF-36, are unable to evaluate changes in the quality of life in the case of certain diseases. The quality of life protocol that we chose has been validated and used in several reported studies, which specifically focused on the symptoms of hyperhidrosis in different daily life situations and on how they affected patients' global quality of life $\mathrm{e}^{2,10,21,22}$.

The only factors that are currently associated with worsened quality of life after surgery are compensatory hyperhidrosis, when severely manifested, and surgical failure. In this study, we observed that the group over 30 years of age presented greater severity of compensatory hyperhidrosis but, nevertheless, it did not report a worsened quality of life. This is probably because these patients are in a psychologically more stable phase in life, and for this same reason are able to better understand the possible complication and endure it better.

In an attempt to search for new prognostic factors, we analyzed the response to the procedure by different age groups and found no significant differences. The 
same levels of quality of life (far better) in the postoperative period were verified in all groups of patients, regardless of their age. In most cases, this surgery immediately eliminates the patient's distress very safely ${ }^{21}$, generating a high level of satisfaction for most patients regardless of their ages.

\section{Conclusion}

Patients with primary hyperhidrosis experience quality of life improvement after thoracic sympathectomy regardless of their ages.

\section{References}

1. Alric P, Branchereau P, Berthet JP, Leger P, Mary H, Mary-Ane C. Video-assisted thoracoscopic sympathectomy for palmar hyperhidrosis: results in 102 cases. Ann Vasc Surg. 2002;16:708-13.

2. De Campos JRM, Kauffman P, Werebe E de C, Andrade Filho LO, Wolosker N. Quality of life, before and after thoracic sympathectomy: report on 378 operated patients. Ann Thorac Surg. 2003;76:886-91.

3. Sugimura H, Spratt EH, Compeau CG, Kattail D, Shargall Y. Thoracoscopic sympathetic clipping for hyperhidrosis: long-term results and reversibility. J Thorac Cardiovasc Surg. 2009;137:1370-6

4. Neumayer $\mathrm{CH}$, Bischof $\mathrm{G}$, Függer R, Imhof $\mathrm{M}$, Jakesz R, Plas EG, et al. Efficacy and safety of thoracoscopic sympathectomy for hyperhidrosis of the upper limb. Results of 734 sympathectomies. Ann Chir Gynaecol. 2001;90:2000-2

5. de Campos JR, Wolosker N, Takeda FR, Kauffman P, Kuzniec S, Jatene FB, et al. The body mass index and level of resection: predictive factors for compensatory sweating after sympathectomy. Clin Auton Res. 2005;15:116-20.

6. Sugimura H, Spratt EH, Compeau CG, Kattail D, Shargall Y. Thoracoscopic sympathetic clipping for hyperhidrosis: long-term results and reversibility. J Thorac Cardiovasc Surg. 2009;137:1370-6

7. Araújo CA, Azevedo IM, Ferreira MA, Ferreira HP, Dantas JL, Medeiros AC. Compensatory sweating after thoracoscopic sympathectomy: characteristics, prevalence and influence on patient satisfaction J Bras Pneumol. 2009;35:213-20.

8. Munia MA, Wolosker N, Kauffman P, de Campos JRM, Puech-Leão P. A randomized Trial of T3-T4 versus T4 sympathectomy for isolated axillary hyperhidrosis. J Vasc Surg. 2007;45:130-3.

9. de Campos JRM, Kauffman P, Wolosker N, Munia MA, de Campos Werebe E, Andrade Filho LO, et al. Axillary hyperhidrosis: T3/ T4 versus T4 thoracic sympathectomy in a series of 276 cases. J Laparoendosc Adv Surg Tech A. 2006;16:598-603.

10. Munia MA, Wolosker N, Kaufmann P, de Campos JR, PuechLeão P. Sustained benefit lasting one year from T4 instead of T3T4 sympathectomy for isolated axillary hyperhidrosis. Clinics. 2008:63:771-4.

11. Wolosker N, Yazbek G, Ishy A, de Campos JR, Kauffman P, PuechLeão P. Is sympathectomy at T4 level better than at T3 level for treating palmar hyperhidrosis? ) Laparoendosc Adv Surg Tech A. 2008;18:102-6.
12. Drott C, Gothberg G, Claes G. Endoscopic transthoracic sympathectomy: an efficient and safe method for the treatment of hyperhidrosis. J Am Acad Dermatol. 1995;33:78-81.

13. Shachor D, Jedeikin R, Olsfanger D, Bendahan J, Sivak G, Freund U. Endoscopic transthoracic sympathectomy in the treatment of primary hyperhidrosis. A review of 290 sympathectomies. Arch Surg. 1994;129:241-4.

14. Lin CC, Wu HH. Lin-Telaranta classification: the importance of different procedures for different indications in sympathetic surgery. Ann Chir Gynaecol. 2001;90:161-6.

15. Jaffer $U$, Weedon $K$, Cameron AEP. Factors affecting outcome following endoscopic thoracic sympathectomy. $\mathrm{Br}$ J Surg. 2007:94:1108-12.

16. Leseche G, Castier Y, Thabut G, Petit MD, Combes M, Cerceau O, et al. Endoscopic transthoracic sympathectomy for upper limb hyperhidrosis: limited sympathectomy does not reduce postoperative compensatory sweating. I Vasc Surg. 2003;37:124-8.

17. Yazbek G, Wolosker N, de Campos JR, Kauffman P, Ishy A, PuechLeão P. Palmar hyperhidrosis--which is the best level of denervation using video-assisted thoracoscopic sympathectomy: T2 or T3 ganglion? J Vasc Surg. 2005;42:281-5.

18. O'riordain DS, Maher M, Waldron DJ, O'donovan B, Brady MP. Limiting the anatomic extent of upper thoracic sympathectomy for primary palmar hyperhidrosis. Surg Gynecol Obstet. 1993;176:151-4.

19. Doblas M, Gutierrez R, Fontcuberta J, Orgaz A, Lopez P, Criado E. Thoracodorsal sympathectomy for severe hyperhydrosis: posterior bilateral versus unilateral staged sympathectomy. Ann Vasc Surg. 2003;17:97-102.

20. Yazbek G, Wolosker N, Kauffman P, de Campos JR, Puech-Leão P, Jatene FB. Twenty Months of Evolution Following Sympathectomy on Patients with Palmar Hyperhidrosis: Sympathectomy at the T3 Level is Better than at the T2 Level. Clinics (Sao Paulo). 2009; 64:743-9.

21. Wolosker N, Yazbek G, Milanez de Campos JR, Kauffman P, Ishy A, Puech-Leão P. Evaluation of plantar hyperhidrosis in patients undergoing video-assisted thoracoscopic sympathectomy. Clin Auton Res. 2007;17:172-6.

22. Amir $M$, Arish $A$, Weinstein $Y$. Impairment in quality of life among patients seeking surgery for hyperhidrosis (excessive sweating). Preliminary results. Isr Psychiatry Relat Sci. 2000;37:25-31.

Correspondence
Marco Antonio Munia
Rua Joaquim Floriano, $820-$ cj 193/194 - Itaim Bibi
CEP 04534-000 - São Paulo (SP), Brasil
E-mail: ma.munia@uol.com.br
Authors contributions
Conception and design: NW, MASM, JRMC
Analysis and interpretation: NW, MASM, JRMC
Data collection: NW, MASM, JRMC
Writing the article: NW, MASM, JRMC, GY, PK, FBJ, PPL
Final approval of the article*: NW, MASM, JRMC, GY, PK, FBJ, PPL
Statistical analysis: NW, MASM, JRMC
Overall responsibility: NW, MASM, JRMC, GY, PK, FBJ, PPL
* All authors have read and approved the final version of the article submitted
to J Vasc Bras.. 